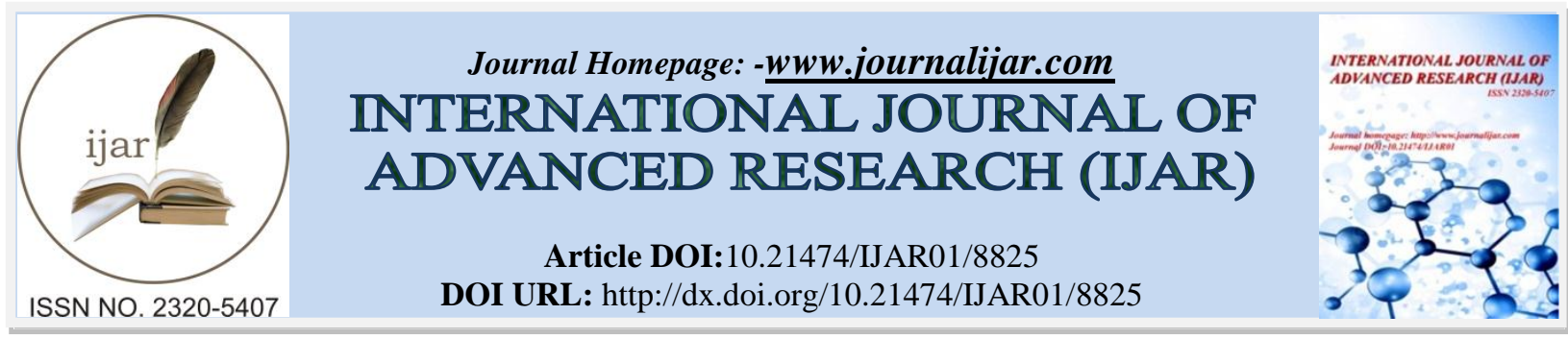

RESEARCH ARTICLE

\title{
TUBERCULOMA OF THE LEFT VENTRICULAR MYOCARDIUM: UNUSUAL LOCALIZATION OF A CASE WITH LITERATURE REVIEW.
}
M. J. Rhissassi, H. Wazaren, H. Bouhdadi, M. M. Maharazou, A. Aghzar, I. Benabderrazak, N. EIMoktadir, I. Maaroufi, C. Benlafqih, R. Sayah and M. Laaroussi.
Cardiovascular Surgery Service A, IbnSina Hospital, Rabat.

\section{Manuscript Info}

Manuscript History

Received: 06 February 2019

Final Accepted: 08 March 2019

Published: April 2019

\section{Abstract}

Copy Right, IJAR, 2019,. All rights reserved.

\section{Introduction:-}

Tuberculosis is still a major cause of morbidity and mortality from infectious diseases. The cardiac locations are dominated by pericardial lesions. There are myocardial attacks that remain exceptional and have diagnostic difficulties. Medical imaging techniques provide diagnostic tools. Sometimes, surgical exploration is necessary, as we report in our observation.

\section{Observation}

This is a 24-year-old patient, admitted for exploration and management of a left ventricular mass evolving in a context of deterioration of the general state. The anamnesis did not find pathological antecedents, notably no tuberculosis nor chronic smoking. The patient reported 4 months before admission a dry cough with atypical chest pain associated with dyspnoea evolving in a context of deterioration of the general state. The patient was febrile, with left basal fluid effusion syndrome on clinical examination. Chest X-ray showed left pleurisy, left para-hilar opacity and moderate cardiomegaly. The thoracic CT complement (Figure 1) showed the presence of a cystic mass of the lower left ventricle with a low abundance of left pleural effusion.

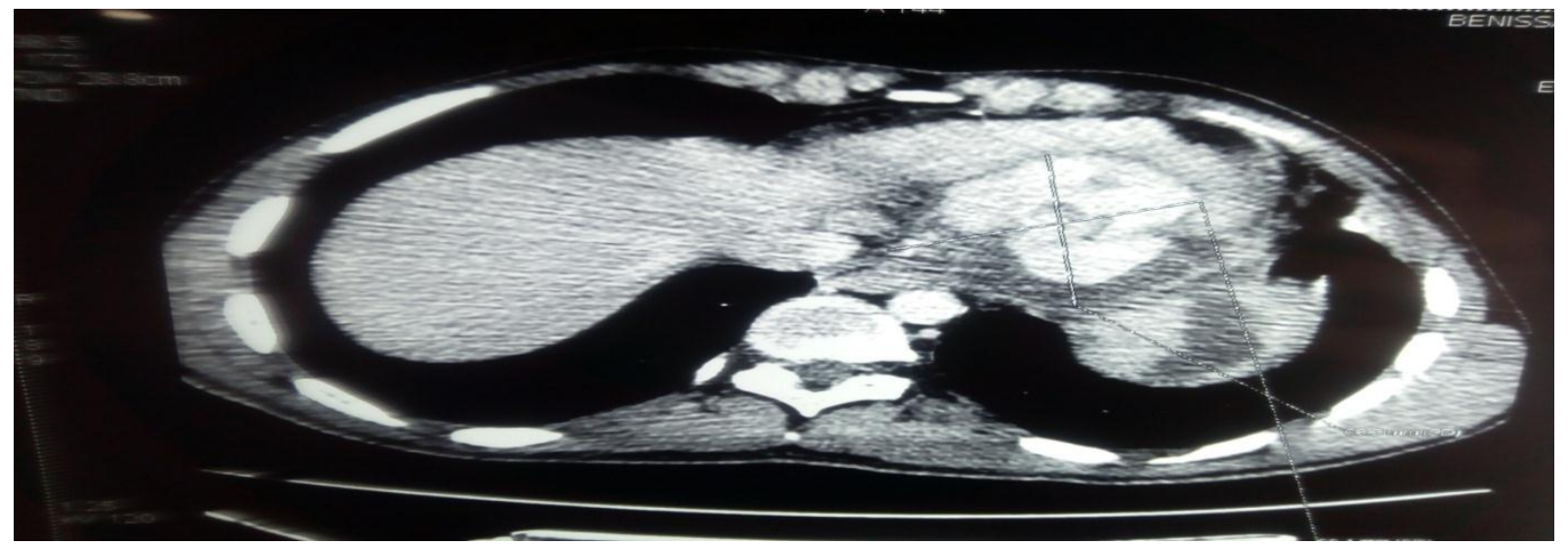

Figure $\mathbf{N}^{\circ}$ 1:-transverse chest CT scan showing the cystic LV mass preoperatively 
Sputum smear in the sputum was negative. The hydatid serology controlled was positive at 49 DU. Transthoracic echocardiography showed the presence of a $25 \mathrm{~mm}$ left infero-ventricular cystic image associated with an intraventricular mobile image with communication between the two masses. Magnetic resonance imaging (Figure 2) confirmed the presence of a cystic mass of the left ventricle.
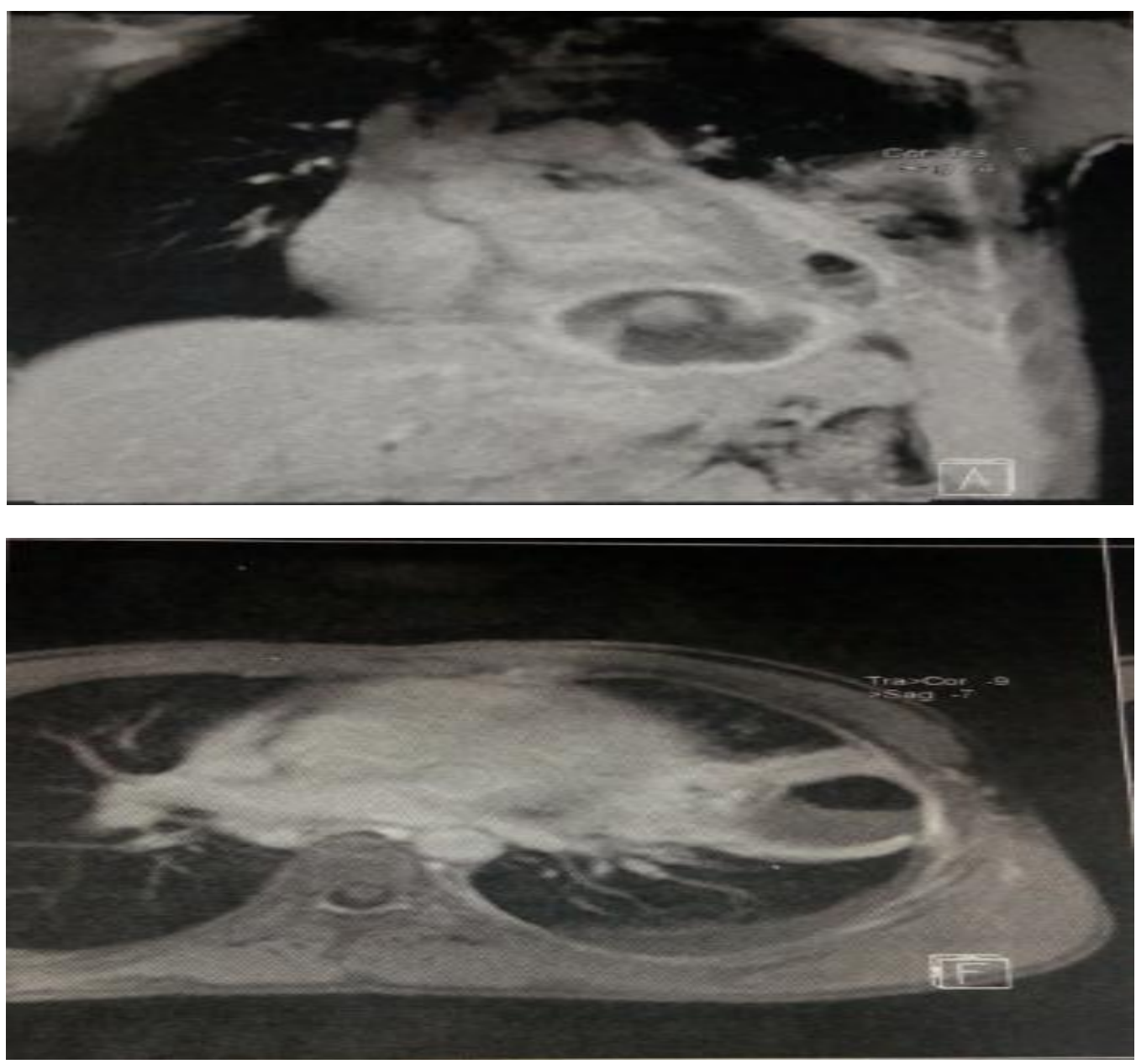

Figure $\mathbf{N}^{\circ}$ 2:-Sections of cardiac MRI showing left inferior ventricular cystic mass.

The decision of the medical-surgical staff was to make a surgical exploration of the cystic mass.

The patient was operated on. He had a sternotomy completed by a left anterolateral thoracotomy. The exploration showed the presence of multiple pericardial granulations with a mass of the tip of the left ventricle. The opening of the mass indicated the presence of thick, yellowish intra-cystic fluid which was sucked up with careful excision of the mass. The pathological study showed a granulomatous epithelio-cellular reaction consistent with tuberculosis. The patient was put on anti-bacillary treatment.

CT scan after one week showed a decrease in mass size (Figure 3). 

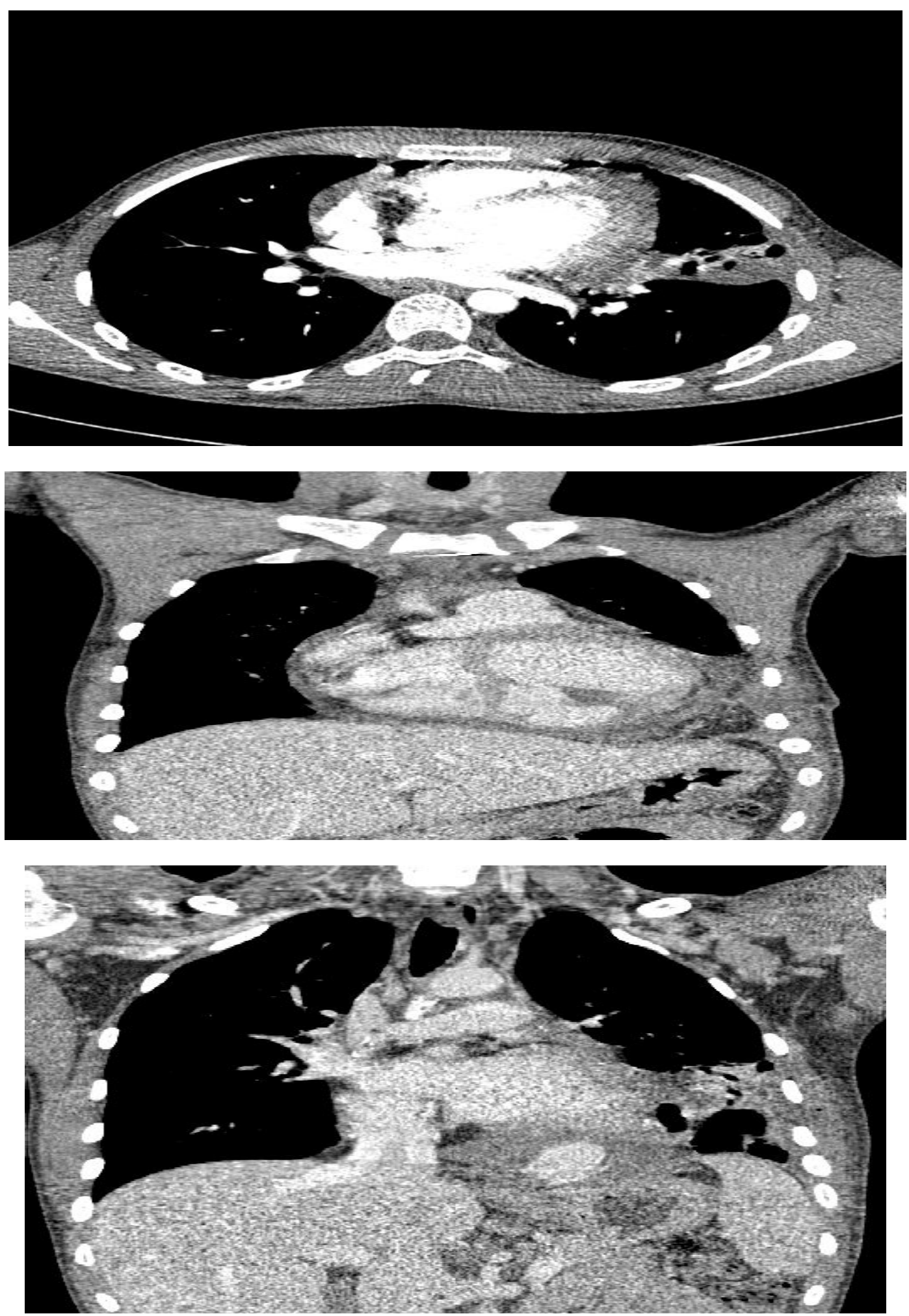

Figure $\mathbf{N}^{\circ}$ 3:-images A, B, C correspond to transverse and coronal CT sections showing the regression of the size of the left ventricular mass after surgery. 


\section{Discussion:-}

Myocardial tuberculomas are exceptional. They have been described in autopsy series with a prevalence of about $0.02 \%$ [1]. Rare cases have been diagnosed in living patients [2].

Myocardial involvement may be responsible for sudden death, disturbances in rhythm or conduction (BAV, long QT, cardiogenic shock or ventricular rupture, explaining that in the majority of cases reported, the diagnosis is autopsic).

Myocardial involvement may be haematogenous, lymphatic, but often it is contiguity from pericarditis or mediastinaltuberculous adenitis. In our case, contiguity is most likely.

Tuberculous lesions of the myocardium may be in diffuse infiltrative form [3], tuberculous myocarditis or as a tumor mass, as the case of our patient.

Myocardial tuberculomas seem to be more frequently located in the right cavities. Localization at the two cavities has recently been reported in the literature [4].

The manifestations of myocardial tuberculosis are variable: rhythm disorders, atrioventricular blocks, congestive heart failure, and aortic insufficiency, compression of the pulmonary veins or superior vena cava by the myocardial mass.

The most common complications are atrial fibrillation and sudden death [5]. Cardiac MRI is currently the most important imaging test in the diagnostic approach. The characteristic aspect in T2 sequence shows a central and peripheral hypointense signal with a hyperintense thin line.

Surgical exploration remains an alternative in litigious cases like ours.

In most published cases, mass regression is almost complete as soon as antituberculosis treatment is initiated.

In the case of large and compressive tuberculomas, surgical resection is necessary and improves the prognosis [6].

\section{Conclusion:-}

The localization of myocardial tuberculosis is rare. It should be sought in case of clinical or paraclinical signs (biology, ECG) in favor of myocardial disease or in case of disseminated tuberculosis. We have powerful and noninvasive diagnostic tools to assert myocardial involvement with MRI. The endomyocardial biopsy (histological examination,), the reference examination to affirm the myocardial attack tuberculous, is reserved for the serious clinical forms or presenting diagnostic difficulties. The prognosis is severe and the early treatment of tuberculosis can be curative.

\section{References:-}

1. Dada MA, Lazarus NG, Kharsany AB, Sturm AW. Sudden death caused by myocardial tuberculosis: case report and review of the literature. Am J Forensic Med Pathol. 2000;21(4):385-8

2. Anzouan-Kacou JB, N'Guetta R, Seka R, Kakou GM, N'Zi KP, Abouo-N'Dori R. Tumeur de l'oreillette gauche à Abidjan (Côte d'Ivoire) Med Trop. 2008 Apr;68(2):179-81.

3. Kapoor OP, Mascarenhas E, Rananaware MM, Gadgil RK. Tuberculoma of the heart: report of 9 cases. Am Heart J. 1973 Sep; 86(3):334-40.

4. Krishnan Rajeshwari, Sandya Gupta, AnandPrakashDubey, Rani Gera. Asymptomatic multiple intracardiactuberculomas in a child. Cardiology Journal. 2012; 19(5):518-520.

5. Wallis PJW, Branfoot AC, Emerson PA. Sudden death due to myocardial tuberculosis. Thorax. 1984 Feb; 39(2):155-6.

6. Krishnaswami H, Cherian G. Right atrial tuberculoma: report of a case with complete recovery. Thorax. 1984; 39(7):550-1. 